\title{
Algunas consideraciones sobre el delito de adulterio: un proceso de finales del siglo XVIII ${ }^{1}$
}

\section{Some considerations about the crime of adultery: a process of the Late Eighteenth Century}

\author{
María José COLLANTES DE TERÁN DE LA HERA \\ Profesora Titular de Historia del Derecho \\ Universidad de Cádiz \\ collantes.teran@uca.es
}

Recibido: 20 de marzo de 2013

Aceptado: 24 de junio de 2013

\begin{abstract}
RESUMEN
Teniendo como base un pleito sobre adulterio suscitado en Valladolid a finales del XVIII, el presente trabajo constituye una reflexión sobre las transformaciones que experimenta este delito en las leyes, en la doctrina y en la práctica judicial a lo largo de los siglos XVIII, XIX y primera mitad del XX. Cuestiones tales como el comportamiento que se considera constitutivo del mismo, la pena con la que suele castigarse, quién tiene derecho a poner en marcha un proceso sobre adulterio, las consecuencias del perdón del marido ofendido, qué ocurría con los hijos adulterinos... Son algunas de las cuestiones tratadas, con las que conseguimos acercarnos a la difícil y dura realidad a la que se enfrentaron las familias que sufrían sus consecuencias.
\end{abstract}

PALABRAS CLAVE: Adulterio, Derecho penal, Siglos XVIII y XIX, Derecho castellano.

\begin{abstract}
On the basis of an adultery lawsuit raised in the Late Eighteenth Valladolid, this work is set as a reflection on the changes taking place in the laws which deal with this crime, as well as the doctrine and judicial practice throughout the $18^{\text {th }}, 19^{\text {th }}$ and first half of the $20^{\text {th }}$. Issues such as the behavior that is considered constitutive of the crime; the penalty with which it is usually punished: who is entitled to launch a process on adultery; the consequences of forgiveness from the offended husband; what happened to children born of adultery ... These are just some examples ot the matters which are dealt in this paper matters, with the goal to get us closer to the hard and difficult reality faced by the families suffering this crime's consequences.
\end{abstract}

KEYWORDS: Adultery, Criminal Justice, $18^{\text {th }}$ and $19^{\text {th }}$ Centuries, Castilian law.

\footnotetext{
${ }^{1}$ Este trabajo forma parte del Proyecto de Investigación titulado "Delincuencia y represión jurídica en España: teoría y praxis histórica de las figuras delictivas II", referencia DER2012-31098 financiado por el Ministerio de Economía y Competitividad del Gobierno de España.
} 


\section{RÉSUMÉ}

Sur la base d'un procès sur adultère soulevé à la fin du XVIII à Valladolid, ce travail est une réflexion sur les changements dans ce delit, qui ont eu lieu dans les lois, la doctrine, et dans la pratique judiciaire tout au long du $\mathrm{XVIII}^{\mathrm{e}}, \mathrm{XIX}^{\mathrm{e}}$ et première moitié du $\mathrm{XX}^{\mathrm{e}}$ siècle. Des questions telles que le comportement constitutif du délit, la pénalité habituellement adscrite, les titulaires du droit à lancer un procès sur adultère, les conséquences du pardon du mari offensé, les conséquences pour les enfants nés d'adultère... Voilà quelques des questions traitées dans le but de nous rapprocher de la réalité dure et difficile rencontrée par les familles subissant les conséquences de ce délit.

MOTS CLÉ : Adultère, justice pénale, XVIII et ${ }^{e} I^{e}$ siècles, droit castillan.

\section{ZUSAMMENFASSUNG}

Basierend auf einem Prozess über einen wiederholten Ehebruch in Valladolid zum Ende des 18. Jahrhunderts, stellt die vorliegende Arbeit eine Reflexion über die Veränderungen dar, die dieses Delikt in den Gesetzen, in der Doktrin und in der praktischen Jurisprudenz in weiten Teilen des 18., 19. und in der ersten Hälfte des 20. Jahrhunderts erfahren hat. Solche Fragen, wie das Benehmen, das für dergleichen als ursächlich betrachtet wurde, die Strafe mit der man sich gewöhnlich kasteite, wer das Recht behielt einen Prozess wegen Ehebruchs anzustrengen, die Konsequenzen der Vergebung durch den beleidigten Ehemann, was mit den Kindern der Ehebrecherin geschah... Das sind nur einige der behandelten Fragen, mit denen sich vorliegend beschäftigt wird und mit denen sich der schwierigen und harten Realität, mit der sich Familien konfrontiert sahen, die unter den Konsequenzen zu leiden hatten, angenähert wird.

SCHLÜSSELWÖRTER: Ehebruch, Strafrecht, 18. und 19. Jahrhundert, kastilisches Recht.

SUMARIO: 1. Introducción. 2. Comportamientos que se consideran constitutivos de este delito y prueba de los mismos. 3. Penas que suelen imponerse. 4. El perdón del marido ofendido. 5. Posible existencia de hijos adulterinos.

\section{Introducción}

El 2 de abril de 1796 la Real Chancillería de Valladolid dicta sentencia definitiva contra $\mathrm{D}^{\mathrm{a}}$ Bernardina Sarabia y D. Josef María de Castro y Caminero, en un pleito sobre "adulterio y reincidencias en trato ilícito y escandaloso". Se trata de una causa iniciada dos años antes por D. Félix Martínez López, médico de Valladolid de 39 años, "Catedrático de Prima de Medicina de la Real Universidad de Valladolid, del Gremio y Claustro de dicha Universidad", contra su mujer — de 27 años-y un abogado, también perteneciente al "Gremio y Claustro de la Real Universidad de Valladolid".

Los hechos tienen lugar en la Castilla de finales del XVIII, por lo que el delito de adulterio que se ha llevado ante la justicia, al menos teóricamente, se rige por las normas de la Nueva Recopilación de Castilla, que en esta cuestión recoge disposiciones del Fuero Juzgo, Fuero Real, Ordenamiento de Alcalá, Ordenamiento de Montalvo y Leyes de Toro, y que luego pasarán a la Novísima Recopilación castellana de 1805.

\footnotetext{
${ }^{2}$ Archivo de la Real Chancillería de Valladolid, Pleitos Criminales, c. 269-2.
} 
Por su parte, la doctrina - tanto los autores que comentan estos textos como los que darán su opinión sobre los distintos Códigos penales españoles - se empeña en aclarar distintas cuestiones relativas a dicha figura delictiva. De ellas, hemos escogido para este trabajo algunas que van surgiendo a lo largo de la lectura del pleito aludido, muy extenso - 406 folios - y que nos va a servir de guía a la hora de reflexionar sobre las transformaciones que experimenta el adulterio en las leyes, en la doctrina y en la práctica judicial a lo largo de los siglos XVIII, XIX y primera mitad del XX. Cuestiones tales como el comportamiento que se considera constitutivo de este delito, la pena con la que suele castigarse, qué permite la ley al marido ofendido cuando descubre in fraganti a su mujer, quién tiene derecho a poner en marcha un proceso sobre adulterio, la diferencia de trato de la mujer y el marido cuando incurren en la misma conducta ${ }^{3}$, qué circunstancias determinan que la mujer adúltera pueda defenderse y quedar exenta de pena, las consecuencias del perdón del marido ofendido, qué ocurría con los hijos adulterinos... Son cuestionen que no agotan, en absoluto, todos los problemas que surgen en torno a este delito pero que nos acercan bastante a la difícil y dura realidad a la que se enfrentaron las familias que sufrían sus consecuencias.

\section{Comportamientos que se consideran constitutivos de este delito y prueba de los mismos}

Sabemos que es muy difícil encontrar en las leyes de los siglos XVI, XVII y XVIII definiciones abstractas de los diferentes delitos. Tomás y Valiente, en su libro sobre el Derecho penal en la Monarquía absoluta ${ }^{4}$, hizo una magistral explicación del tipo delictivo fragmentado y descriptivo característico de la España moderna. Destacó la insuficiencia de las definiciones legales de los delitos, la indeterminación de su naturaleza, su sometimiento al arbitrio judicial en la valoración de los supuestos y en la determinación de la pena, la falta de una noción abstracta de cada delito y la frecuencia de las meras descripciones casuísticas de las conductas antijurídicas, o la composición atomizada mediante diversas leyes de una sola figura delictual ${ }^{5}$. En cambio, en los tipos delictivos elaborados por la doctrina - tanto jurídica como teológicael grado de plenitud y de abstracción que alcanzan las figuras delictivas es incomparablemente superior al que manifiesta la legislación ${ }^{6}$.

Para el caso del delito de adulterio, sí encontramos una definición en las Partidas, en concreto a la Ley 1, Título 17, Partida 7, en cuyas primeras líneas puede leerse:

\footnotetext{
${ }^{3}$ Sobre esta cuestión, M.J. Collantes de Terán de la Hera, El amancebamiento: una visión histórico-jurídica en la Castilla moderna, Madrid, Dikynson, S.L., de aparición inminente (2014).

${ }^{4}$ F. Tomás y Valiente, El Derecho penal en la Monarquía absoluta (siglos XVI-XVII, XVIII), Madrid, 1969.

${ }^{5}$ Son palabras de Álvarez Cora refiriéndose al libro de Tomás y Valiente (E. Álvarez Cora, La tipicidad de los delitos en la España moderna, Madrid, Dykinson, S. L., 2012, p. 15).

${ }^{6}$ Ibidem.
} 
"Adulterio es yerro que ome face á sabiendas, yaciendo con mujer casada ó desposada con otro: E tomó este nombre de dos palabras del latin alterius et thorus, que quieren tanto decir, como ome que va ó fue al lecho de otro; por cuanto la mujer es contada por lecho del marido con quien es ayuntada é non el della..."

Si nos centramos en qué acción es la que se considera constitutiva del adulterio, comprobamos que el legislador utiliza el verbo yacer. En el siglo XVII Sebastián de Covarrubias habla de "ayuntamiento carnal" cuando define el término "adulterar": "Es tener ayuntamiento carnal con persona que es casada, o siendo ambos los que se juntan casados, y haciendo traición a sus consortes". A continuación define "adulterio" como "el tal ayuntamiento ilícito"7. Son palabras semejantes a las que se utilizan un siglo después en el Diccionario de la lengua castellana de $1732^{8}$ para definir adulterio: "El acto torpe de ayuntamiento carnal de hombre con mujer casada, o de mujer con hombre casado".

Por tanto, determinar cuál es la conducta delictiva parece fácil, sólo el acto de yacer - y no otro tipo de comportamientos- es el que se considera propio del delito, pero el problema surge a la hora de probar que se ha llevado a cabo. Los sujetos activos del delito, lógicamente, van a ser precavidos y harán lo posible por evitar ser sorprendidos. Lo más habitual será que no sean descubiertos en el momento de incurrir en tal conducta, por lo que la justicia tendrá que entrar a valorar actitudes, situaciones, comportamientos, que hagan presuponer o constituyan indicios de que el acto de yacer, en que consiste el adulterio, se ha producido. En el pleito en cuestión, por el testimonio de las criadas, sabemos que "el Dr. D. Josef de Castro entraba y salía a todas horas, de día y de noche en la casa de sus amos, tratando y comunicando con la $\mathrm{D}^{\mathrm{a}}$ Bernardina con una familiaridad más que regular, acompañándola a los paseos y cuantos ratos podía o tenía ocasión... concurría también a la casa cuando su amo no estaba en ella". En el memorial de queja con el que se inicia el proceso, D. Félix, el marido, describe con detalle los hechos que se han producido y que para él son constitutivos del delito. En primer lugar, dice tener noticia "del rumor, nota, y escandalo que con motivo de las frecuentes entradas en su casa, del doctor Don Josef Castro y Caminero, se habían subscitado en la vecindad y en la maior parte del pueblo, y con algunas fundadas sospechas de que no se dirigían a fines honestos...". Para evitar "la ocasión de todo daño", el día 1 de febrero de 1794 escribió y entregó personalmente una esquela ${ }^{9}$ a Castro prohibiéndole que volviera a su casa y que hablara con

\footnotetext{
${ }^{7}$ S. de Covarrubias Orozco, Tesoro de la Lengua castellana o española, Madrid, 1611 (Ed. de Felipe C.R. Maldonado, revisada por Manuel Camarero, Editorial Castalia, $2^{\mathrm{a}}$ ed. corregida, Madrid, 1995, p. 21). ${ }^{8}$ Real Academia Española, Diccionario de Autoridades, edición facsímil, Gredos, Madrid, 1990, 3 vols. ${ }^{9} \mathrm{El}$ tenor de la misma era el siguiente: "Señor Don Josef Castro Caminero: Las frecuentes entradas de vmd, en mi casa, son el objeto de la murmuración de todos, ofendiendo el honor de mi mujer, y mas el mio; con su conducta yniqua que no ignoro, sin embargo de la hombría de bien que aparenta: en este supuesto vmd se abstendrá de venir a mi casa, y jamas volverá a tratar a mi mujer, ni aun ablarla, y de no hacerlo asi, se expondrá a sufrir la venganza de un marido justamente irritado. Hoy primero de Fevrero de mil setecientos noventa y quatro. Félix Martinez Lopez".
} 
su mujer en ninguna circunstancia, y a ella le hizo una severa reprensión, prohibiéndole que bajo ningún pretexto le permitiese la entrada en la casa ni le hablase en ningún sitio. A partir de ahí surgen riñas en el matrimonio, $\mathrm{D}^{\mathrm{a}}$ Bernardina abandona el hogar familiar y se va a casa de un médico amigo de la familia, quien logra convencerla de que vuelva con su marido — también allí fue visitada por Castro-, D. Félix enferma por los disgustos y parece que no cesaron de mediar recados entre ambos ${ }^{10}$; en realidad era ella la que se los mandaba continuamente con algún sirviente para que acudiera a verla a su casa o a otros lugares. Los hechos que finalmente llevaron al marido a presentar el memorial de queja ante la justicia tuvieron lugar la noche del tres de febrero y, especialmente, la mañana del día cuatro. Aprovechando que D. Félix estaba enfermo en cama, su mujer y Castro lograron verse el día 3 por la noche "retirándose para ello a una pieza destinada a despensa (que es la mas oculta de la casa), y no tiene paso para ninguna otra" y al día siguiente, en que "tubo noticia el que expone, a las nueve y media de su mañana, de que se hallavan ocultos y a solas en el mismo parage". D. Félix, "a pesar de estar recientes dos sangrías que se havia hecho", se levantó de la cama y con una navaja grande en la mano "y con animo de vengarse del agravio que su imaginación le representaba, con la maior viveza, y le hacia estar sin la reflexion necesaria para obrar con cordura en aquel lance: Se dirigió efectivamente á dicha pieza de despensa, y prevenidos los que estaban dentro por un grito que dio una criada, asustada al verle en aquella disposición, afianzaron el picaporte para impedir que entrase". Un boticario que casualmente estaba de visita en la casa, al oir todo el jaleo, consiguió con mucho esfuerzo quitarle la navaja a D. Félix "a fin de impedir el grave daño que amenazava", y cuando aquél consiguió abrir la puerta después de golpearla repetidamente con un utensilio que había cogido de la cocina, el boticario pudo contenerle cuando se abalanzó sobre Castro, a quien sólo consiguió quitarle el manteo que tenía puesto y hacerle caer el sombrero. Castro salió corriendo a la calle sólo con la sotana y ella fue detrás "en ropas menores ${ }^{11}$, con grandísima mofa de toda la vecindad, que se hallaba asomada a las ventanas, y de una multitud de otras gentes, especialmente estudiantes que pasavan por la calle".

Entre todos estos sucesos, no vemos que en ningún momento se hable de "yacimiento" o de "ayuntamiento carnal"; pero el mero hecho de estar los dos solos y escondidos en una habitación es suficiente para que el marido considere que han

\footnotetext{
10 “...postrado en cama de resulta de las desazones consiguientes a su situación, y de una tenaz tos que padecia; a pesar de el dolor y quebranto, con que venia afligido su animo, y a pesar de las amorosas y tiernas expresiones con que este procuró hacerla entrar en su deber, y restablecer la paz del matrimonio, con que la convidava, sin exigir de ella mas que el avandono de sus devaneos; supo con el mas vivo dolor, que desde aquel tiempo no cesaron de mediar recados, dirigidos por dicha Doña Bernardina al Doctor Castro, para satisfacer a el deseo de su mutua pasión...”.

${ }^{11}$ Se especifica que salió en enaguas, a cuerpo ( $\sin$ chal o prenda similar) y sin medias ni zapatos. De hecho, las criadas le tuvieron después que enviar a la casa donde se había refugiado "calzonas, basquiña, manteleta y mantilla".
} 
incurrido en adulterio. Sí se insiste en que los interesados aprovechan generalmente la ausencia del marido para verse en la casa, pero siempre hay criados cerca que son testigos de las frecuentes conversaciones entre ambos - aunque disimulen y bajen la voz cuando ellos aparecen-. Parece a propósito traer aquí las palabras de Joaquín Escriche cuando indica que para probar que el adulterio se ha cometido, se reputan bastantes "las presunciones vehementes; por ejemplo, la que nace de haber encontrado a los adúlteros acostados en un mismo lecho ó en tal disposición que manifieste el acceso carnal". Y añade que la ley 12, tít. 14, Part. 3 y la 12, tít. 17, Part. 7, "tiene por justificado el adulterio, si receloso alguno de que otro le hace ó intenta hacer agravio con su mujer le requiere tres veces por escritura de escribano público ó ante testigos para que se abstenga de tratarla, y aun la corrije a ella para que no hable con él, y despues los encuentra juntos conversando en su casa ú otra, ó en huerta ó casa distante de la villa ó sus arrabales" $"$. Algunas de estas condiciones, aunque no en su literalidad, aparecen en el caso, como la esquela que entrega el marido ofendido a su oponente o la reprensión y prohibición que le hace a su mujer de volver a hablar con el abogado.

Estos sucesos acabaron con un auto, dictado el 1 de marzo de 1794, en el que se condenaba a $\mathrm{D}^{\mathrm{a}}$ Bernardina a salir por un año de la ciudad y residir en el pueblo y casa a que la destinase su marido, tiempo que no cumple entero porque, a petición de ella, el marido accede a restituirla a su casa. Pero la historia tiene una segunda parte, pues poco tiempo después de que volviese al hogar con su marido, éste se da cuenta que los recados y los encuentros entre la pareja continúan y a partir de entonces D. Félix se dedica a vigilarlos constantemente para poder probar ante la justicia la infidelidad de su mujer. Sin embargo, los encuentros que se describen distan mucho de parecerse a yacimientos o ayuntamientos carnales. Vamos viendo cómo $\mathrm{D}^{\mathrm{a}}$ Bernardina y Castro se empeñan en conseguir cruzarse en paseos públicos, coincidir en actos religiosos en las Iglesias y, a lo sumo, en verse en alguna huerta, todo bajo la mirada inquisidora de los vecinos del pueblo, que están pendientes del mínimo paso que dan. Son situaciones menos comprometidas aún que las que habían dado lugar a la primera condena, y que habían consistido en lo que ella misma describe en una carta que le escribe a su marido mientras está en el pueblo en el que fue obligada a permanecer durante un año: “...ya se acabaron para mí los paseos, las dispersiones, los juegos, las conversaciones y cuanto hasta aquí me ha tenido engañada".

Finalmente, D. Félix consigue lo que estaba buscando para poner una acusación formal. Con ocasión de salir fuera de la ciudad a una visita médica, deja vigilando a su pasante y cuatro discípulos, dándole al primero una llave de su casa y poderes para que "haga lo mismo que haría él y de parte al Receptor del Concejo para lo que acae-

\footnotetext{
${ }_{12}$ J. Escriche, Diccionario razonado de legislación y jurisprudencia, Nueva edición reformada y considerablemente aumentada por los Doctores D. Leon Galindo y de Vera y D. José Vicente y Caravantes, Tomo Primero, Madrid, 1874, “Adulterio", p. 321.
} 
siese". En efecto, Castro entra por la noche, hacia las doce, pero cuando se dispone a salir a las tres de la madrugada los espías, que estaban dentro de la casa, los detienen a los dos y avisan a la justicia ${ }^{13}$. El 8 de diciembre de 1794 se inicia, así, un segundo pleito que comienza con la presentación por parte de D. Félix de otro Memorial de queja ante la justicia, diciendo que han reincidido en sus tratos "juntándose en parajes y sitios ocultos, Iglesias, huertas, paseos públicos y en casa de María Alonso, y en su casa estando el fuera...". D. Félix presenta su acusación criminal contra ellos por los delitos de adulterio y reincidencia en trato y comunicación escandalosa e ilícita. Durante el proceso aclara que en la causa anterior se había abstenido de proponer una acusación formal de adulterio, contentándose con pedir una Providencia gubernativa, con el fin de ver si por este medio lograba la enmienda y corrección de su mujer. Pero cuando creyó que estaba enmendada y que tendría una conducta intachable, comprobó que no era así. Los testimonios que van dándose durante la causa, especialmente de las criadas y, sobre todo, el de una antigua sirvienta de Castro, María Alonso Ibáñez, nos van a dar una idea de cómo la conducta de los implicados se va agravando y la convivencia del matrimonio va siendo cada vez más insostenible. Se habla de Iglesias en las que estuvieron juntos o a pocos pasos de distancia, donde quizás se hacían señas "o alguna otra gestión indecorosa", "incluso se habían dado la mano por la espalda". Una criada declaraba que "no había Iglesia ni paseo en que no se encontrara con Castro y la gente ya lo notaba", "incluso cuando iba a misa iba a buscar a Castro". La misma le había dicho a $\mathrm{D}^{\mathrm{a}}$ Bernardina "que la veía muy perdida, que le pidiese a su marido que la pusiese en un convento hasta que se le olvidara aquella malvada pasión". Y que D. Félix le había dicho que ya estaba cansado de reprenderla, y que no lograba más que le perdiese el respeto y le llenase de ignominias. Otra criada de la casa cuenta cómo Castro se metía allí y había que sacarlo por la puerta del corral cuando llegaba el marido. A María Alonso Ibáñez la utilizaban como correo, y Da Bernardina le hablaba del "mal trato, despego y disgusto que le daba su marido". Cuando la reprendía él, algún amigo o doméstico con "caritativas amonestaciones", ella respondía "con algún nuevo estravio o prorrumpía con expresiones escandalosas contra su marido" 14 .

Todas estas situaciones podían constituir indicios de que el delito se estaba cometiendo, pero para poder interponer la acusación formal el marido tuvo que aportar

13 "Castro prometió ausentarse si lo soltaban, pero ella no daba palabra de dejar de tratar con Castro. Este la reconvenia con que le tenía dicho que su marido tenía espías y temeroso solicitó que no dejasen entrar a D. Félix porque este no vengase las injurias que le había irrogado, lo que no debía de haber hecho, por ser un hombre de bien". Estas palabras, por la que los protagonistas se autoinculpaban del delito cometido, fueron dichas delante de todos los presentes, incluido el Receptor del Consejo que había acudido avisado por el pasante de D. Félix.

${ }^{14}$ Un vecino la había oído decir dos veces que "tenía odio a su marido, que oxala le llevaran los Demonios antes de que volviese a casa, que no quería vivir con el, y si separarse de su compañía". Las criadas le habían escuchado también palabras como estas: "maldito sea mi marido. Si se muriera, aunque le viera hir por el rio abaxo no le havia de dar la mano". 
pruebas, como fueron el hecho de que se habían juntado en la casa de María Alonso durante más de hora y media - lo que le valió a dicha María la pena de destierro-, y sobre todo el poder detener a Castro en su propia casa de madrugada. Esos hechos sí pueden incluirse en las "presunciones vehementes" de las que hablaba Escriche, quien aludía como dijimos a que en las Partidas y para el delito de adulterio se admitían las pruebas de indicios ${ }^{15}$ - igual que en el Fuero Juzgo ${ }^{16}$ - , haciéndose una excepción al criterio general de prueba legal por el que había optado el código alfonsino, frente al de la prueba moral o de indicios ${ }^{17}$.

\section{Penas que suelen imponerse}

A finales del siglo XVIII las penas establecidas por el legislador para los adúlteros hay que buscarlas en la Nueva Recopilación de Castilla, que da preferencia al Fuero Juzgo y al Fuero Real — frente a las Partidas - en lo relativo al modo de castigar este delito, imponiendo penas de índole personal y patrimonial. Se establece así que los adúlteros sean puestos en manos del marido para que haga de ellos lo que quiera; se le permite, incluso, matar a ambos, pero no a uno sólo, quedándose además con sus bienes, salvo que tuviesen hijos legítimos, pues en este caso serán éstos quienes tengan derecho a dichos bienes ${ }^{18}$. Las Partidas, en cambio, siguiendo el derecho romano, castigaba a la mujer con azotes públicos y reclusión en un monasterio, con pérdida de la dote, arras y bienes gananciales a favor del marido, y a su cómplice con la pena de muerte ${ }^{19}$.

\footnotetext{
${ }^{15}$ Partidas 3,4,12: “...Pero cosas y a señaladas, en que el pleyto criminal se prueua por sospechas, maguer no se auerigue por otras prueuas. E esto seria, quando alguno que ouiesse sospecha de otro, que le faze, o que fazer tuerto de su mujer..."; Partidas 7,17,11: "Como se puede prouar, e aueriguar el adulterio, por razón de sospecha. Averiguarse puede el adulterio a las vegadas, non tan solamente por prueuas, mas aun por sospechas...".

${ }^{16}$ Fuero Juzgo 3,4,3: "Si la muier casada faze adulterio, é non la prisieren con el adulterio, el marido la puede acusar antel iuez por sennales é por presunciones é por cosas que sean convenibles...".

${ }^{17}$ Como se indica ya en el encabezamiento de Partidas 3,4,12: "Como el pleito criminal non se puede prouar por sospechas, si non en cosas señaladas".

${ }^{18}$ Nueva Recopilación 8,20,1 (=Novísima Recopilación 6,28,1): "Que pone la pena de los adulteros. Si mujer casada fiziere adulterio, ella y el adulterador amos sean en poder del marido, y faga dellos lo que quisiere, y de quanto han, asi que no pueda matar al uno y dexar al otro: pero si hijos derechos ouieren ambos, ó el uno dellos, hereden sus bienes. Y asi por ventura la mujer no fue en culpa, y fuere forçada, no aya pena". Fuero Real 4,7,1: "Si mujer casada ficiere adulterio, ella y el adulterador, amos sean en poder del marido, è faga dellos lo que quisiere, è de quanto han: asi que no pueda matar al uno, è dexar al otro...”. Fuero Juzgo 3,4,1: “....si el adulterio fuere fecho de voluntad de la muier, la muier é el adulterador sean metidos en mano del marido, e faga dellos lo que se quisiere”. Fuero Juzgo 3,4,2: “...ella y el adulterador, ó el otro marido, ó el otro esposo sean metidos en poder del primer esposo por siervos con todas sus cosas...".

${ }^{19}$ Partidas 7,17,15: "Que pena merece el hombre o la mujer que face adulterio... Acusado seyendo algund ome, que ouiesse fecho adulterio, si le fuesse prouado que lo fizo, deue morir por ende. Mas la mujer que fiziesse el adulterio, maguer le fuesse prouado en juyzio, deue ser castigada e ferida pública
} 
El origen de esa "facultad de matar" recogida en nuestra legislación puede encontrarse - como señala Machado Carrillo ${ }^{20}$ — en un texto del Fuero Juzgo que dispone que "si el marido e el esposo mata la mujer hy el adulterador, non peche nada por el omecillo" 21 . Como hemos visto, las leyes exigían que el marido matara a ambos o a ninguno, salvo en las Partidas, que no imponían la pena de muerte a la adúltera, salvo "si la mujer casada fuesse probado que fiziesse adulterio con su siervo... deven ser quemados ambos a dos por ende"22. El Fuero Real hacía también una excepción para la mujer desposada que cometía adulterio, que sería puesta junto con su cómplice en poder del esposo, al que no le está permitido matarlos ${ }^{23}$, si bien el Ordenamiento de Montalvo $(8,15,2)$, reproduciendo el texto literal de la Ley 1, Título 21 del Ordenamiento de Alcalá, suprime dicha prohibición, recogiéndose así en la Nueva Recopilación ${ }^{24}$.

En concreto, aquella disposición del Ordenamiento de Alcalá —que después se recogió en los otros textos - facultaba al marido para matar a los adúlteros si los sorprendía en el mismo acto o in fraganti, con tal que quitase la vida a los dos, y no a uno solo. Con ello querría evitarse - nos dice Escriche - que de esta manera el marido, de acuerdo con su mujer, matase a un rival o enemigo suyo, o de acuerdo con un tercero matase a su mujer ${ }^{25}$. Si el marido no quería o no podía hacerlo, dispuso esta misma ley, con arreglo a la del Fuero Real, que si acusare y probare el delito fuesen puestos en su poder los adúlteros, para que de ellos y su bienes hiciese lo que quisiera $^{26}$.

mente con açotes. E puesta, e encerrada en algún Monasterio de dueñas. E demás desto, deue perder la dote, e las arras que le fueron dadas por razón de casamiento, e deuen ser del marido...".

${ }^{20}$ M.J. Machado Carrillo, El adulterio en el derecho penal. Pasado, presente y futuro, Valencia, 1977.

${ }^{21}$ Fuero Juzgo 3,4,4. Este "beneficio" se extiende al padre y a los hermanos y tíos de la adúltera, una vez muerto el padre, si el adulterio tuene lugar en la casa paterna (Fuero Juzgo 3,4,14 y 3,4,5; Fuero Real 4,7,6; Ordenamiento de Montalvo 8,13,4; Nueva Recopilación 8,23,4; Novísima Recopilación $12,21,1)$.

${ }^{22}$ Partidas 7,17,15.

${ }^{23}$ Fuero Real 4,7,2.

${ }^{24}$ Nueva Recopilación 8,20,3 (=Novísima Recopilación 12,28,2): Que la mujer desposada si hiziere adulterio, aya la misma pena que la casada. Contienese en el fuero de las leyes, que si la muger que fuere desposada hiziere adulterio con alguno, que ambos a dos sean metidos en poder del esposo, assi que sean sus siervos: pero que no los pueda matar. Y porque esto es exemplo y manera para muchas dellas de hazer maldad, y meter en ocasion y verguença a los que fuesen desposados con ellas, porque no puedan casar en vida dellas: porende tenemos por bien por escusar este yerro, que passe de aqui adelante en esta manera. Que toda mujer que fuere desposada por palabras de presente con hombre que sea de catorce años cumplidos, y ella de doze años acabados, e hiziere adulterio, si el esposo los hallare en uno que los pueda matar si quisiere a ambos a dos: assi que no pueda matar al uno, y dexar al otro, pudiendo los ambos a dos matar...”.

${ }^{25}$ J. Escriche, Diccionario razonado..., tomo primero, "Adulterio", p. 319.

${ }^{26}$ Nueva Recopilación 8,20,3 (=Novísima Recopilación 12,28,2): “...Y si los accusare a ambos o a qualquier dellos, que aquel contra quien fuere juzgado, que lo metan en su poder, y haga de el y de sus bienes lo que quissiere...". 
La ley 82 de Toro había establecido que el marido que matara a los adúlteros, aunque fuese en el hecho o in flagrante delicto, no ganase la dote, ni los bienes del muerto, copiándose así en la Nueva Recopilación ${ }^{27}$.

Todas estas penas - a pesar de que, como hemos visto, se recogen después en la Novísima Recopilación de 1805- habían caído en desuso en la época a la que nos venimos refiriendo y reciben las críticas de la doctrina. Escriche, por ejemplo, se detiene en ir calificándolas una a una negativamente. Señala, así, que

"la pena capital es demasiado rigurosa, y no tiene proporción ni analogía con el delito; y la de azotes á las mujeres es contraria al decoro y á las costumbres. La de poner á los adúlteros en poder del marido para que disponga de ellos como quisiere, equivale á volvernos legalmente en este punto al estado natural en que no había leyes, pues por ella se resucita la venganza individual [...] La ley que permite al marido quitar la vida á los adúlteros que sorprende en el hecho, adolece igualmente de los mismos vicios; reviste á un hombre fuera de si, de la sagrada autoridad de magistrado, haciéndole juez en su propia causa; entrega al furor ciego, la espada que nunca debe empuñar sino la impasible justicia; expone al ofendido á ser víctima de los esfuerzos reunidos de los dos ofensores, y prepara tal vez un plausible pretexto á algún marido inicuo para deshacerse traidoramente de una mujer á quien aborrece, ó de un rival ó enemigo que le hace sombra. Pues no está bastante precavido este riesgo con la condición que se impone al marido de matar á los dos ó á ninguno, respecto de que esta condicion, según el concepto de la ley, no se ha de verificar absolutamente, sino solo en el caso que sea posible"28.

\section{Joseph Berni pone de manifiesto el desuso en que habían caído estas penas cuando indicaba que}

"En primer lugar, no he visto, ni oído exemplar, en estos tiempos, de que los adúlteros sean entregados al marido para que les mate, ò haga lo que quiera de ellos; lo que he visto en práctica es: perdonar al marido porque mató à los adulteros: pero no se escusó de una larga prisión, mientras se hazia la averiguación, y después un destierro según las circunstancias. En segundo lugar se verán decisiones superiores mas suaves unas, que otras, porque el arbitrio de juez tempera, avida consideración à las circunstancias, y personas delinquentes. Pero lo regular es, que si la adultera es de mediana esfera, entra en clausura, y al hombre se le destierra; y si acontece en gente baxa, se encarcela la mujer, y el hombre va à presidio"29.

\footnotetext{
${ }^{27}$ Nueva Recopilación 8,20,5 (=Novísima Recopilación 12,28,5): Que el que matare por su propia autoridad a los adulteros, no gane la dote y los bienes sino matándolos con autoridad de la justicia. El marido que matare por su propia autoridad al adultero y a la adultera, aunque los tome in fragrante delicto, y sea justamente hecha la muerte, no gane la dote ni los bienes del que matare: salvo si los matare o condenase por autoridad de nuestra justicia: que en tal caso mandamos, que se guarde la ley del fuero que en este caso dispone, que es la ley primera de este titulo".

${ }^{28}$ J. Escriche, Diccionario razonado ..., tomo primero, "adulterio", pp. 320-321.

${ }^{29}$ J. Berno, Práctica criminal con nota de los delitos, sus penas, presunciones y circunstancias que los agravan y disminuyen y ritual para juzgar, acriminar y defender en los Tribunales reales de España y en los particulares de Residencias, $2^{\mathrm{a}}$ edición, Valencia, 1765, Lib. I, cap. I, pp. 7-8.
} 
También insiste en ello Álvarez Posadilla, indicando que el desuso de aquellas normas se debía a que los maridos, generalmente, se contentaban con la reclusión de la mujer ${ }^{30}$. González Serrano, por su parte, apunta que desde la promulgación de las Leyes de Toro fue cayendo cada vez más en desuso la pena de poner a los adúlteros en manos del marido, y añade que no recuerda ningún proceso ni en su siglo ni en el anterior - el XVIII - en que se hubiera impuesto la pena de muerte por el simple adulterio, ni menos aún que se hubiera permitido que el marido matase impunemente a los adúlteros ${ }^{31}$.

Si han caducado las penas establecidas por las leyes, se pregunta Escriche, qué castigo debe imponerse a los adúlteros, teniendo en cuenta el daño causado al ofendido ${ }^{32}$. Y responde que los tribunales suelen castigar al adúltero con la pena de destierro, presidio o multa, y a la adúltera con la de reclusión, regulando y agravando más o menos estas penas según las circunstancias ${ }^{33}$. A este atemperamiento de las penas ya se había referido, como vimos antes, Joseph Berni, quien entendía que la mayor o menor suavidad de las mismas dependía de las personas y circunstancias, y señalaba para la adúltera la pena de clausura (o la de encarcelamiento si era de baja condición) y para el adúltero la de destierro (o la de presidio para los de baja condición).

${ }^{30} \mathrm{~J}$. Álvarez Posadilla, Comentarios a las Leyes de Toro según su espiritu y el de la legislación de España, $3^{\mathrm{a}}$ impresión, Madrid, 1826 (la $1^{\mathrm{a}}$ edición se publica en Valencia en 1796), ley 80, p. 311.

${ }^{31}$ J. González Serrano, Comentario histórico, crítico y jurídico a las Leyes de Toro, t. II, Madrid, 1876, ley 82 , p. 469.

${ }^{32}$ El citado autor especifica cuáles son exactamente estos daños que sufre el marido ofendido: “... privase al marido por el adulterio de aquella dulce ilusión que le lisonjeaba de poseer exclusivamente el corazón de su esposa; se le desvanece la esperanza de poder gozar en adelante los placeres mas puros del amor; se vierte sobre su corazón la copa de la amargura; se le hace una herida profunda en el honor, pues que se cree objeto de cierta especie de menosprecio, sabiendo que la opinión pública suele señalar con el dedo á los que reciben tales injurias, quizá por suponerlas efecto del modo de conducirse los maridos con sus mujeres; se le expone tal vez á verse perjudicado en el órden económico de la casa, y á tener que hacer participante de sus bienes á un hijo extraño en perjuicio de los propios ó de los demás herederos legítimos" (J. Escriche, Diccionario razonado ..., tomo primero, "adulterio", p. 320).

33 "Digo según las circunstancias — aclara Escriche-, porque mayor pena merece, v. gr., la mujer que habiéndose casado con el objeto de su elección quiebra luego caprichosamente los lazos que se formara ella misma, que no aquella infeliz que, llevada arrastrando el ara por un extraño interés, no dio sino con labio trémulo el si fatal que desmentían su corazón y la palidez de su semblante: mayor pena merece la mujer imprudente que, obstinándose en el olvido de su deber, se complace tal vez en hacer gala de su extravio, que no la mujer bien educada y sensible que habiéndose dejado seducir por la ilusión de un momento, no puede soportar la idea de su infidelidad: mayor pena merece la mujer que engaña á un esposo tierno que la adora y se desvive por complacerla, que no la desgraciada que no viendo en su marido mas que un desleal que desprecia su amor, ó tal vez un tirano que la atormenta, se aprovecha por fin del alivio, aunque ilícito y falso, que su justo dolor se le depara. Tambien influyen las circunstancias en la mayor ó menor pena del adúltero, y así el que estando en una casa en calidad de huésped, amigo, dependiente, criado, etc., comete adulterio con la esposa, hija ó parienta del jefe de la familia ó con la nodriza de algún hijo de este mismo, es castigado por el abuso de confianza con mas rigor que cualquier otro sugeto que no tiene iguales relaciones; bien que no está en uso la pena capital ni la de azotes que respectivamente les imponia la ley 2, tit. 29, lib. 12, Nov. Recop.” (Ibidem, pp. 320-321). 
Como hemos dicho ya, el pleito del que nos venimos ocupando incluye dos causas. Con la primera el marido ofendido, según indica él expresamente, sólo pretende obtener una "Providencia Gubernativa con el fin de ver si con este medio lograba la enmienda y corrección de su mujer", consiguiendo que el 1 de marzo se dicte un auto en los siguientes términos: "Se previene a $\mathrm{D}^{\mathrm{a}}$ Bernardina que en lo sucesivo se porte con prudencia y sea más obediente a su marido, absteniéndose del trato con personas que no sean de la voluntad y confianza de este, y en particular con el Dr. D. Josef Castro Caminero, con quien en tiempo alguno trate ni comunique en publico ni en secreto; Y por no haberlo hecho, se la condena a que por un año salga de esta ciudad, y resida en el Pueblo y Casa que la destinase su marido, los seis meses primeros precisos, y los seis restantes a voluntad de éste, a quien se haga saber...”. Por su parte, respecto al Dr. Castro, por gozar de fuero académico, se pasa la causa al Rector de la Universidad, quien, tras iniciar el proceso con un auto de oficio el 21 de febrero de 1794, determina primero su arresto en su domicilio; posteriormente, "para que no se experimente retraso ni perjuicio alguno en la Enseñanza pública" se relaja dicho arresto a la ciudad y arrabales, dictándose auto definitivo el 28 de junio de 1794, por el que se le condena a un mes de ejercicios en el Convento del Abrojo, prohibiéndole entrar nunca más en casa de D. Félix, ni tratar de palabra ni por escrito con su mujer, y se le condena en todas las costas causadas, dándose por terminada la causa.

Pero como se puso de manifiesto en la segunda causa abierta contra ellos, los acusados continuaron en contacto incluso mientras ella se encontraba en la villa de Baloria, a la que la había enviado su marido, y desde que volvió con éste al hogar conyugal, por lo que D. Féliz, en cuanto consiguió las pruebas necesarias, inició una segunda causa con una acusación criminal por adulterio y reincidencia en trato ilícito y sospechoso, siendo ambos trasladados el 17 de abril de 1795 a la cárcel, y dictándose la sentencia definitiva el 2 de abril de 1796, por la que se condenó a $D^{a}$ Bernardina Sarabia a ocho años de reclusión, "en el parage que señalare su marido" y a D. Joseph Maria Castro a ocho años de reclusión en el Castillo de Fuente de la Concepción. D ${ }^{a}$ Bernardina, además, fue condenada a la pérdida de su dote y arras, las cuales "haia y disfrute aquel [su marido] como propias con la reserva que previene el derecho si tuviere en la actualidad hijo o hijos legítimos de dicha su mujer", y ambos mancomunadamente en todas las costas de la causa, "y se les apercibio que si en lo subsesivo reincidiesen en iguales excesos serán castigados con maior rigor".

Es evidente, ya lo hemos dicho, que en el siglo XVIII se aprecia una importante disminución de la gravedad de los castigos, que se manifiesta primero en la práctica judicial, y que después se irá trasladando a los códigos penales del XIX y primera mitad del XX. En éstos, se suavizan extraordinariamente las penas impuestas a este delito por nuestra antigua legislación, consideradas por los autores como excesivamente duras, e imponen otras proporcionadas a las que se venían aplicando en la práctica de los tribunales.

El Código de 1822 castiga a la mujer, además de a perder todos los derechos de la sociedad conyugal, a sufrir una reclusión por el tiempo que quiera el marido, con 
tal de que no sea superior a diez años; el cómplice seguirá la misma suerte que la mujer y será desterrado del pueblo mientras viva el marido ${ }^{34}$.

El Código de 1848 supuso un gran avance con respecto al que le precedió. Como indica Vaello Esquerdo, el hecho de que el art. $349^{35}$ contenga una definición del adulterio y el haberle suprimido al marido la facultad de fijar la pena — que será la de prisión menor- son innovaciones trascendentales ${ }^{36}$. Dicha pena es calificada por los autores como "no muy dura" ${ }^{37}$ y "proporcionada" 38 .

Entre las reducidas novedades que trae consigo el Código penal de 1870 se encuentra precisamente el cambio de pena, castigándose el delito de adulterio con prisión correccional en sus grados medio y máximo, esto es, de dos años y cuatro meses a seis años ${ }^{39}$. Con ello la pena sufre una disminución en su margen mínimo, que de cuatro años pasa a dos años, cuatro meses y un día.

En cuanto al marido que mataba a los adúlteros cuando los sorprendia in fraganti, el art. 438 del Código penal de 1870 no considera el acto de matarlos como causa de exculpación completa, sino de aminoración de la pena, al disponer que el marido que sorprendiendo en adulterio a su mujer matare en el acto a ésta o al adúltero, o les causare lesiones graves, será castigado con la pena de destierro. Solamente cuando las lesiones que se causaren a los adúlteros no fuesen graves, es absoluta la exención ${ }^{40}$.

Hay autores que critican esta reducción de las penas establecidas por los códigos en un delito como el adulterio: "Esta penalidad parece poco grave atendida la criminalidad del adulterio - puede leerse en la edición aumentada del Diccionario razonado de legislación y jurisprudencia de Escriche, en la parte comentada por los doctores

\footnotetext{
${ }^{34}$ Art. 683: "La mujer casada que cometa adulterio perderá todos los derechos de la sociedad conyugal, y sufrirá una reclusión por el tiempo que quiera el marido, con tal de que no pase de diez años. Si el marido muriera sin haber pedido la soltura, y faltare más de un año para cumplirse el término de la reclusión, permanecerá en ella la mujer un año después de la muerte del marido; y si faltare menos tiempo, acabará de cumplirlo. El cómplice en el adulterio sufrirá igual tiempo de reclusión que la mujer, y será desterrado del pueblo mientras viva el marido, a no ser que éste consienta otra cosa".

35 "El adulterio será castigado con la pena de prisión menor. Cometen adulterio la mujer casada que yace con varón que no sea su marido, y el que yace con ella sabiendo que es casada, aunque después se declare nulo el matrimonio".

${ }^{36}$ E. Vaello Esquerdo, Los delitos de adulterio y amancebamiento, Barcelona, 1976, p. 30.

${ }^{37}$ T.M ${ }^{\mathrm{a}}$ de Vizmanos y C. Álvarez Martínez, Comentarios al Código penal, tomo II, Madrid, 1848, p. 366.

${ }^{38}$ J.F. Pacheco, El Código penal concordado y comentado, $6^{\mathrm{a}}$ ed., tomo III, Madrid, 1888, p. 104.

${ }^{39}$ Art. 448: "El adulterio será castigado con la pena de prisión correccional en sus grados medio y máximo. Cometen adulterio la mujer casada que yace con varón que no sea su marido y el que yace con ella, sabiendo que es casada, aunque después se declare nulo el matrimonio".

${ }^{40}$ Art. 438: "El marido que sorprendiendo en adulterio a su mujer matare en el acto a ésta o al adúltero, o les causare alguna de las lesiones graves, será castigado con la pena de destierro. Si les causare lesiones de otra clase, quedará exento de pena. Estas reglas son aplicables en iguales circunstancias a los padres respecto de sus hijas menores de veintitrés años y sus corruptores, mientras aquéllas vivieren en la casa paterna. El beneficio de este artículo no aprovecha a los que hubieren promovido o facilitado la prostitución de sus mujeres o hijas".
} 
León Galindo y de Vera y José Vicente y Caravantes-, puesto que en este hecho se cometen tres crímenes, uno contra la Divinidad por el perjurio sacrílego a la fé jurada en los altares; otro contra la sociedad, y otro privado, por la injuria causada al esposo con la alteración de las relaciones íntimas en la familia y el ataque a la legitimidad de la prole"41, y detectan en la opinión pública una tolerancia con estas situaciones que no comparten ${ }^{42}$. A pesar de ello, destacan el aspecto positivo de las penas impuestas en la nueva legislación (se refieren al Código de 1870 concretamente) pues "ofrecen la ventaja de ser á propósito para la enmienda del culpable; puesto que la soledad en que le coloca y la privación del trato de su familia, le harán aspirar á los goces del hogar doméstico y reconocer su falta. La pena de prisión combinada con la facultad de perdonar concedida al marido... es el único y mas seguro correctivo de la pena del adulterio, puesto que castiga y repara á la vez, satisface la vindicta pública, venga el honor privado y no impide la reconciliación conyugal; purifica á los culpables, enfrena sin violencia las costumbre y corrije la opinión del pueblo"43.

Junto a estas críticas contra la disminución de la gravedad de las penas, en el siglo XVIII empiezan a proliferar opiniones (como las del Voltaire y Filangieri) contrarias a la punición del adulterio; de hecho, la tendencia abolicionista va ganando terreno en las legislaciones modernas ${ }^{44}$. A comienzos del XIX cuando, en relación a la represión del delito de adulterio, surgen dos tendencias de gran importancia: una intenta instaurar la igualdad de tratamiento entro los esposos; la otra tiende a la no incriminación del adulterio, conociéndose esta última por corriente abolicionista. En virtud de la misma, se pone de manifiesto cómo el adulterio pertenece al campo más íntimo y privado de la familia y considera que la intervención de la ley penal lo único que consigue son unas consecuencias funestas ${ }^{45}$ - como dificultar la reconciliación y contribuir a romper irremediablemente los lazos familiares ${ }^{46}$.

${ }^{41}$ J. Escriche, Diccionario razonado ..., tomo primero, “adulterio", p. 326.

42 "A pesar de constituir este hecho uno de los mas graves atentados contra las costumbres, con oprobio de la moral, la opinión pública parece excusar lo que la ley debe reprimir, mostrando una especie de interés hacia el culpable y una especie de irrision hacia la victima" (Ibidem).

${ }^{43}$ Ibidem.

${ }^{44}$ M. del R. Diego Díaz-Santos, Los delitos contra la familia, Madrid, 1974, p. 186 y ss.

${ }^{45}$ Ibidem, p. 213 y ss. Esta autora opina, no obstante, que no se puede desconocer el resquebrajamiento que el adulterio supone para el matrimonio, pues en algunos supuestos incluso puede disociar la familia mediante la introducción de una filiación ilegítima y, en consecuencia, perturbar de una manera indirecta el orden social. En esto se basan aquellos que son partidarios de su represión, argumentando que la intervención del Derecho penal es necesaria a fin de que mediante la amenaza de la sanción, se descarte el peligro que el adulterio supone para la sociedad. Aunque hay que tener en cuenta — añade — que no siempre el adulterio supone de manera inevitable una ruptura del vínculo matrimonial, entendido éste en un sentido amplio, pues en gran parte de los supuestos dichas conductas no suponen más que una brecha pasajera en la vida conyugal (Ibidem, pp. 213-214).

${ }^{46}$ Como indica ya en nuestros días J.M Rodríguez Devesa, Derecho penal español. Parte Especial, $5^{\mathrm{a}}$ ed., 1973, p. 172. 
El Código de 1928 fija la pena para los adúlteros en uno a tres años de prisión, y se atenúa considerablemente - multa de mil a dos mil pesetas - si los cónyuges estaban legalmente separados ${ }^{47}$. Pero en cuanto se proclama la Segunda República el Gobierno provisional declaró anulado este Código penal y restableció el de 1870, mientras se iba elaborando un nuevo texto. En atención a que la Ley de Divorcio de 12 de marzo de 1932 consideraba la infidelidad como una causa de disolución del matrimonio, el adulterio - y el amancebamiento - fueron suprimidos como delitos en el Código penal de 1932.

Tras la derogación de la Ley de divorcios por el Estado Nacional, vuelven a incriminarse adulterio y amancebamiento en la Ley de 11 de mayo de 1942, pues de lo contrario hubieran quedado sin castigo. Esta ley recoge en un artículo único la regulación del Código de 1870, señalando como pena para el adulterio la de prisión menor y omitiendo el párrafo "aunque después se declare nulo el matrimonio", que se recuperaría después en el Código de $1944^{48}$. La nueva normativa quedó completada con la reincorporación del art. $428^{49}$, que tipificaba el parricidio honoris causa, y cuyo precedente más directo era el art. 438 del Código de 1870. En atención al mismo, el marido que matare a los culpables sorprendidos en adulterio sólo sufría la pena de destierro ${ }^{50}$.

Machado Carrillo indica que lo grave de la existencia de esta "facultad de matar", es que indirectamente supone el mantenimiento de la pena de muerte en unos delitos para los cuales fue legalmente suprimida. La pena del marido por el susodicho uxoricidio es tan ridícula, que podemos de facto afirmar el mantenimiento de la muerte como posible castigo del adulterio de la mujer hasta $1964^{51}$.

\section{El perdón del marido ofendido}

Otra cuestión importante a la que nos conduce la lectura del proceso estudiado es la del perdón por parte del marido ofendido, que puede o bien llevarle a no acusar a

\footnotetext{
${ }^{47}$ Art. 620: "La mujer casada que yace con varón que no sea su marido, y el que yace con ella sabiendo que es casada, aun cuando se declare posteriormente nulo el matrimonio, incurrirán en la pena de uno a tres años de prisión [...] Cuando el cónyuge culpable de alguno de los delitos previstos en los párrafos precedentes esté legalmente separado del otro cónyuge, o hubiese sido abandonado por el mismo, la pena para cada uno de los culpables será la multa de 1.000 a 2.000 pesetas".

${ }^{48}$ Art. 449: "El adulterio será castigado con la pena de prisión menor. Cometen adulterio la mujer casada que yace con varón que no sea su marido y el que yace con ella, sabiendo que es casada, aunque después se declare nulo el matrimonio".

49 "El marido que, sorprendiendo en adulterio a su mujer matare en el acto a los adúlteros o a alguno de ellos, o les causare cualquiera de las lesiones graves, será castigado con la pena de destierro. Si les produjese lesiones de otra clase, quedará exento de pena. Estas reglas son aplicables, en análogas circunstancias, a los padres respecto de sus hijas menores de 23 años y sus corruptores, mientras aquéllas vivieren en la casa paterna. El beneficio de este artículo no aprovecha a los que hubieren promovido, facilitado o consentido la prostitución de sus mujeres o hijas".

${ }^{50}$ E. Vaello Esquerdo, Los delitos de adulterio..., pp. 33-34. Como señala esta autora, el conyugicidio honoris causa sería suprimido en el Texto revisado de 1963.

${ }^{51}$ M.J. Machado Carrillo, El adulterio ..., p. 51.
} 
su mujer, o bien a perdonarla una vez que se ha pronunciado la sentencia, estando ya cumpliendo el castigo que se le hubiera impuesto, constituyendo dicho perdón una causa de irresponsabilidad. El marido, por tanto, tenía la posibilidad en cualquier momento de remitir la pena a su consorte.

Escriche afirma que en los casos en que la mujer casada incurría en adulterio, sólo podía reparar de algún modo el honor de su marido si daba pruebas "nada equívocas de un sincero y cordial arrepentimiento" 52 . Palabras muy parecidas son las que utiliza D. Félix en el primer proceso para referirse al posible perdón de su esposa. El mismo se produciría solamente cuando ella diera "pruebas seguras de un verdadero arrepentimiento y enmienda". En el memorial de queja con el que iniciaba el proceso, tras explicar con detalle lo que había sucedido, exigía las penas correspondientes para ambos adúlteros "por haber vulnerado su honor gravísimamente en el concepto del público, y ante la imposibilidad de poder vivir en pacífica unión con su mujer, mientras no se consiga su corrección por medio de una estrecha recolección, en que de pruebas de su arrepentimiento y enmienda". Sabedora de ello, $\mathrm{D}^{\mathrm{a}}$ Bernardina, encontrándose ya en el pueblo de Valoria, en el que había sido desterrada durante un año por disposición judicial, remite a su marido el 13 de mayo una carta ${ }^{53}$ con la que pretende demostrarle un sincero arrepentimiento y enmienda, acreedor de su perdón, en la que le ruega que le permita volver a su casa, en su compañía ${ }^{54}$. El 7 de julio de aquel año de 1794, presentó un Memorial en el que suplicaba que se la dispensase de la pena que sufría impuesta a consecuencia de la queja de su marido ${ }^{55}$. Éste condescendió y el 10 de julio se estimó la solicitud de $\mathrm{D}^{\mathrm{a}}$ Bernardina, que volvió a su casa sin haber cumplido el tiempo de destierro que le había sido señalado ${ }^{56}$.

\footnotetext{
52 J. Escriche, Diccionario razonado ..., tomo primero, "adulterio", p. 320.

${ }^{53}$ En ella le dice "que por haverse venido de confesar parecía que Dios la estaba instando a que le hiciese demostración de los afectos de que estaba posehida; Que no pretendía volver a su casa en los términos que presumía D. Félix, pues estaba desengañada de lo que daba de si el mundo, y que para ella se habían acabado, paseos, diversiones, juegos, conversaciones, y cuanto hasta allí la había tenido engañada, que estaba tan enteramente demudada que asi misma no se conocía, y que finalmente estaba tan emmendada, que prometia esta, en términos de no darle el menor disgusto, suplicándole con las mas bibas ansias la volviese a su casa, de la que la podría hechar, y poner en donde, como, y cuando quisiese, siempre que le diese el menor motivo de quexa".

${ }^{54}$ Tras la lectura completa de los dos procesos el carácter de $\mathrm{D}^{\mathrm{a}}$ Bernardina se dibuja como el de una mujer de un carácter caprichoso y difícil. Sólo dos meses antes de escribir esta carta a su marido, recién llegada a su lugar de destierro, había presentado una "memoria o representación" a la justicia en la que indicaba que "todo es debido al genio de su marido, que habrá hecho de ella ante la justicia una agria representación contra ella, pintando su conducta con los más feos colores. Que de ninguna manera se de crédito a lo que el furor celoso de su marido habrá expuesto" y lo describe diciendo que es "de aquellos fanáticamente celosos, para quienes la acción más indiferente suele ser un delito y la mujer más timorata no es la primera vez que ha sido tenida por prostituta".

${ }^{55}$ Alega que la casa a la que la mandó su marido en Valoria estaba en ruinas, era muy pequeña y ella estaba a punto de dar a luz, queriendo evitar "un funesto accidente a ella o al feto".

56 “... [el marido] no halla reparo en que se dispense a esta del tiempo que le resta a cumplir del que se
} 
El perdón del marido ofendido era una de las causas por las que la mujer se eximía de la acusación y de la pena de adulterio. En las Partidas ya estaba previsto que el perdón del marido extinguiera la responsabilidad penal ${ }^{57}$. Escriche indica al respecto que si el marido tuviera a su mujer a sabiendas en su compañía después del adulterio, o la admitiera en su lecho, o dijere ante el juez que no quería acusarla, o abandonara la acusación intentada, se presumía entonces el perdón ${ }^{58}$. El mismo autor indica también otras causas que eximen igualmente a la mujer de la acusación y de la pena de la adulterio: si hubiesen pasado cinco años sin que el marido la hubiese acusado, si el marido hubiese consentido el adulterio, si hubiese cometido el delito creyéndose viuda, si el matrimonio fue nulo por falta de consentimiento o si acreditase que había sido forzada ${ }^{59}$.

El mismo autor afirma que el adúltero, excepto en el caso de fuerza, se exime igualmente de la acusación y de la pena en todos los casos en que se libera la mujer, entre ellos en el supuesto de que hubiese obtenido el perdón gratuito del marido. Aunque debe tenerse en cuenta que si después de la sentencia perdonase el marido a su mujer la pena que se le hubiera impuesto a voluntad del mismo, no por eso deberá dejar de cumplir la suya el adúltero ${ }^{60}$.

En el Fuero Real se había establecido que si el marido no la quería acusar, ni quería que otro lo hiciera, "ninguno no sea rescibido por acusador en tal fecho como este" "ca pues que él quiere perdonar a su mujer este pecado, no es derecho que otro gelo

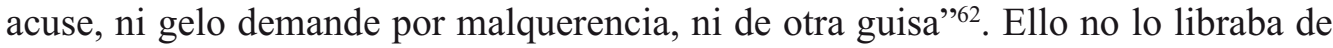
consecuencias negativas pues no estaba bien visto el perdonar. Por ello establecía que al marido que conociera del adulterio de su mujer y no lo denunciara, se le ordenaba que no la tuviera "á su mesa ni en su lecho", y al que "lo fiziere, no la puede después acusar ni haber nada de sus bienes" ${ }^{\prime 63}$. Machado Carrillo ve en estas disposi-

mandó como preciso, dejándola en libertad para que pueda obtener de dicho su marido el que la restituia a su casa y compañía".

${ }^{57}$ Siguiendo el Derecho romano, concretamente la Lex Julia de adulterii coercendis, donde se establecía, en relación al perdón del marido, que si éste no expulsaba de su lado a la adúltera, esto era causa de extinción de la responsabilidad.

${ }^{58}$ Así se había establecido en Partidas 7,17,8 y Fuero Real 4,7,5 (J. Escriche, Diccionario razonado..., tomo primero "adulterio", p. 321).

${ }^{59}$ Ibid.

${ }^{60}$ Ibid., p. 322.

${ }^{61}$ Fuero Real 4,7,1. En el Fuero Juzgo a los maridos que concen la infidelidad y, a pesar de ello, no la persiguen los llama "sandios” (Fuero Juzgo 3,4,13: “... E facen á sus maridos ser sandios por algunas yerbas que les dan, é por algún malfecho, así que magüer que ellos saben el adulterio del mujer, non lo pueden acusar, nin se pueden quitar de su amor dellas"), y da derecho para que la acusen a los hijos, y a falta de éstos, o si son pequeños o por amor no denuncian a la madre, a los "parientes más propinquos del marido" (Fuero Juzgo 3,4,13).

${ }^{62}$ Fuero Real 4,7,3.

${ }^{63}$ Fuero Real 4,7,5. 
ciones cómo el legislador hace todo lo contrario a incitar a perdonar a la mujer, igual que había hecho el Fuero Juzgo ${ }^{64}$.

Como hemos dicho, fueron las Partidas las que establecieron la posibilidad de que el marido pudiera reconciliarse con su mujer y sacarla del monasterio en que estuviere recluida en el plazo de dos años, en cuyo caso recobraba ella la dote, arras y gananciales; pero si no la quería perdonar o moría antes de los dos años, entonces ella debía tomar el hábito del monasterio para siempre ${ }^{65}$. Igualmente establecía que la acción de acusar correspondía a su cónyuge, "pero si el marido fuese tan negligente que non la quisiesse acusar... entonces la podría acusar el padre, é si el padre non lo quisiesse fazer, puédenla acusar uno de los parientes sobredichos [hermanos y tíos] della; más los otros del pueblo non lo pueden fazer" ${ }^{\prime 66}$. En cualquier caso, nadie podía acusar a la mujer cuando el marido hubiera consentido, recibido a su mujer en su lecho a sabiendas del adulterio, o fuera hombre vil.

En la Nueva Recopilación se redujo ya la legitimación para acusar al marido ofendido, que además quedaba obligado a acusar "a los dos siendo vivos o a ninguno"67. "El adulterio es un delito doméstico — diría Escriche-; y mientras el marido no se queja, nadie tiene derecho de quejarse: ni el magistrado mismo puede introducirse á conocer de él por via de pesquisa: la ley quiere que se respete el interior de las familias, y que la mano de la justicia ó de un extraño no arroje en su seno la tea de la discordia. Además este delito causa al ofendido cierta especie de afrenta por efecto de nuestras injustas preocupaciones, y no era justo que la ley por vengar los derechos ultrajados de un marido permitiese la acusación á otro que á el; añadiendo un mal á otro mal. El marido conoce mejor las circunstancias en que le conviene ó no proceder contra sus ofensores" ${ }^{\prime \prime 8}$. E insiste en que el ministerio fiscal no tiene el ejercicio de la acción para castigar el delito de adulterio si no se promueve a instancia del marido ofendido. Y ello porque es más un delito contra el marido, a quien afecta en su honor, que contra la sociedad y en consecuencia "de él depende no dar lugar a inquisiciones judiciales, ahogando sus agravios en el secreto del hogar doméstico"69.

Groizard resalta las dos tendencias o espíritus que hay en nuestra legislación de dicha época en esta cuestión. Una de origen puramente nacional, de ascendencia visigoda, y la otra importada, la del Derecho romano ${ }^{70}$. La que realmente configuraba la vida jurídica era la primera, pero la segunda, desde su posición doctrinal, influyó

\footnotetext{
${ }^{64}$ M.J. Machado Carrillo, El adulterio..., p. 45.

${ }^{65}$ Partidas 7,17,15.

${ }^{66}$ Partidas 7,17,2.

${ }^{67}$ Nueva Recopilación 8,19,7 y 8,20,2 (=Novísima Recopilación 12,26,4). De acuerdo con ello, fue D. Félix quien acusó a su mujer y a Castro.

${ }^{68}$ J. Escriche, Diccionario razonado ..., tomo primero, "adulterio", p. 321.

${ }^{69}$ Ibid., p. 323.

${ }^{70}$ A. Groizard y Gómez de la Serna, El Código penal de 1870, concordado y comentado, t. V, Salamanca, 1983, p. 43, n. 4.
} 
a lo largo del tiempo, de modo que acabó aceptándose el perdón del marido ofendido y la exclusión de extraños en nuestra codificación ${ }^{71}$. Desde el Código penal de 1822, ratificando lo prescrito en la Nueva y Novísima recopilación, sólo se concede al marido la posibilidad de acusar a los adúlteros ${ }^{72}$. Ello se funda - insiste Escriche - en que, si bien los delitos de sensualidad, y en especial el de adulterio, "como atentatorios contra la severidad de las costumbres, que es uno de los vínculos mas fuertes de las familias y de la sociedad, deben ser castigados por el legislador, la ley social debe penarlos solamente cuando se cometen con perjuicio de tercero, dejando á este la facultad de reclamar su castigo y de hacerlos públicos; mas no en el caso contrario y cuando permanezcan en secreto..." 73 .

El Código penal de 1848 establece igualmente que "no se impondrá pena por delito de adulterio sino en virtud de querella del marido agraviado", que deberá hacerlo contra ambos culpables si ambos vivieran, y nunca si hubiere consentido el adulterio o perdonado a cualquiera de ellos ${ }^{74}$. Dispone expresamente que el marido "podrá en cualquier tiempo remitir la pena impuesta a su consorte volviendo a reunirse con ella. En este caso se tendrá también por remitida la pena al adúltero"75.

Escriche indica que lo prescrito en las Partidas sobre que la acusación debía entablarse dentro del término de cinco años contados desde la perpetración del adulterio quedó derogado por el art. 132 del Código penal de 1870, en el cual se establece que la responsabilidad penal se extingue “... $7^{\circ}$ por la prescripción de la pena”; y en el 133, que previene que los delitos prescriben " ... a los diez años cuando señalare la ley al delito penas correccionales", como se verifica respecto del adulterio, y que el término de la prescripción comience a correr desde el día en que se hubiere cometido el delito, y si entonces no fuera conocido, desde que se descubra y se empiece a proceder judicialmente para su averiguación y castigo. Esta prescripción se interrumpe

\footnotetext{
${ }^{71}$ M.J. Machado Carrillo, El adulterio..., p. 46.

${ }^{72}$ Aunque en este texto se incluyen algunos casos en que habría una especie de compensación de delitos que haría que el marido no pudiera acusar a su mujer por adulterio (art. 684: "El marido de la adúltera, que es el único que puede acusar el adulterio, no podrá hacerlo en ninguno de los casos siguientes: Primero: Si ha consentido a sabiendas el trato ilícito de su mujer con adúltero. Segundo: Si voluntaria y arbitrariamente separa de su lado y habitación a la mujer contra la voluntad de ésta o la abandona del mismo modo. Tercero: si tiene manceba dentro de la misma casa en que habite con su mujer".

73 “...porque la acusación pública y las diligencias para averiguar su perpetración abrirían el santuario del hogar doméstico y someterian la vida privada y las acciones íntimas á procedimientos que perjudicarían á la moral y al buen ejemplo. Así, pues, cuando el inmediatamente interesado en su castigo no se presenta á promoverlo, el legislador ha dejado la reprobación y penalidad de tales delitos á la conciencia y á la honestidad públicas y al juicio justo y severo de la Divinidad" (J. Escriche, Diccionario razonado ..., tomo primero, "adulterio", p. 324).

${ }^{74}$ Art. 350. Lo mismo se establece en el art. 449 del Código penal de 1870 (disposición ratificada en los arts. 4 y 6 de la Ley provisional de Enjuiciamiento criminal de 1872), en el art. 621 del Código penal de 1928 y en el 450 del Código penal de 1944.

${ }^{75}$ Art. 351 del Código penal de 1848, art. 450 del Código penal de 1870, art. 622 del Código penal de 1928 y art. 451 del Código penal de 1944.
} 
desde que el procedimiento se dirija contra el culpable, volviendo a correr de nuevo el tiempo de la prescripción desde que aquél termine sin ser condenado o se paralice el procedimiento, salvo por rebeldía del procesado ${ }^{76}$.

\section{Posible existencia de hijos adulterinos}

Antes de terminar esta breve aproximación a la evolución que ha experimentado en nuestro pasado jurídico el tratamiento dado al delito de adulterio, quisiera incidir en un tema que a pesar de que no se trata expresamente durante el proceso que está siendo objeto de nuestro estudio, va apareciendo de forma vedada a medida que se avanza en su lectura. Y no es otro que el de la posible existencia de hijos adulterinos. En la primera parte del mismo nada nos hace sospechar la aparición de esta cuestión, puesto que D. Félix, el marido ofendido, en su memorial de queja, no hace ningún tipo de comentario en relación al mismo. La primera sorpresa nos la encontramos cuando nos enteramos que su mujer está embarazada. En la petición que ella hace a la justicia de que se le permita terminar con su destierro en la villa de Valoria —en la que había sido condenada a residir durante un año-- alega que se encuentra al final de su embarazo y que la casa no tiene las condiciones necesarias para garantizar su seguridad y la de la criatura que va a nacer. Esto ocurre por el mes de mayo, y resulta inevitable hacer una rápida cuenta atrás para comprobar que aquel niño habría sido concebido alrededor del mes de octubre, sólo dos meses antes de que D. Félix llevara ante la justicia por primera vez el adulterio de su mujer. Pero es en las declaraciones hechas en el segundo proceso donde se nos ofrecen algunos detalles bastante sospechosos. Una criada de la casa, Petra Zalama, cuenta cómo, tras haber aconsejado a su ama que pidieran perdón a su marido "por su obsecación y lo que le había ofendido con el trato de Castro", el 27 de noviembre de aquel año, consiguió que entrara en su estudio y así lo hiciera, por lo que su marido "pensando que este cristiano procedimiento fuese arrepentimiento verdadero de su mujer, le sirvió de mucho consuelo y gusto". Pero el mismo día — nos sigue contando — a las tres de la tarde, "olvidada de su fingido arrepentimiento mando a la criada a visitar a Castro, que se hallaba enfermo y que le llevase a su hijo párvulo". Aparece en escena, como vemos, el niño que, probablemente, ya había nacido en el hogar conyugal, puesto que ella fue liberada de su destierro y retornada allí en el mes de julio. Lo curioso es que la criada se esfuerza en recalcar en su declaración lo que ya le había contado a D. Félix, que había ido a visitar a Castro de parte de su ama, "y al mismo tiempo para que viese al niño... con el que la criada manifestó haber hecho aquel muchos halagos y cariños". La misma sirvienta, al relatar todo lo que ocurrió la noche en que Castro fue sorprendido saliendo de la casa a las tres de la madrugada, al referirse al momento en que ya se lo llevaba la justicia, dice que le pidió que se despidiera de su parte de su ama (los tenían

\footnotetext{
${ }^{76}$ J. Escriche, Diccionario razonado ..., tomo primero, "adulterio”, p. 327.
} 
retenidos en habitaciones separadas), "dándole delicados besos y haciendo tiernos cariños al niño que tenía la testigo en brazos".

No sabemos si respecto a este niño D. Félix llegó a plantear realmente algún problema una vez que $\mathrm{D}^{\mathrm{a}}$ Bernardina fue apresada y condenada, posteriormente, a ocho años de prisión. Pero estos hechos nos pueden servir de aliciente para al menos dejar planteado el tema de los hijos adulterinos. Como es sabido, se consideraba como tales a los nacidos de mujer casada y de varón distinto al que estaba unida en matrimonio y se incluían dentro de los hijos ilegítimos ${ }^{77}$, que en un sentido genérico eran todos aquellos que hubieran nacido de una relación extramatrimonial y que no han sido legitimados o no han podido serlo por los medios que el derecho establece.

Dentro de los hijos ilegítimos, los adulterinos -junto con los incestuosos- han sido siempre los que han tenido una peor consideración social y jurídica a lo largo de nuestra historia, en contraposición a los hijos naturales, que son los más favorecidos ${ }^{78}$. Para los primeros el ordenamiento jurídico se ha limitado a reconocerles el derecho a los alimentos cuando son necesarios para el mantenimiento de la vida del hijo, derecho que se reconoce a todo tipo de personas por ilícita o escandalosa que haya sido la unión en la que fueron engendradas ${ }^{79}$.

Joaquín Escriche, en relación a los hijos adulterinos, hace una reflexión muy a propósito de lo que ha ocurrido en el caso del que nos hemos ocupado, y que podía aplicarse directamente a $\mathrm{D}^{\mathrm{a}}$ Bernardina: "Si la mujer tiene un hijo de adulterio ignorándolo el marido, ¿qué debe hacer en conciencia? Si está dudosa sobre la calidad del hijo por haber tenido acceso promiscuamente con el adúltero y el marido, no deber perder su tranquilidad en ninguno de ambos fueros: ley 9, tít. 14, Partida 3. Mas si estuviere cierta, debe hacer de modo que el hijo se abstenga de la herencia paterna,

\footnotetext{
${ }^{77}$ Sobre este tema, E. Gacto Fernández, La filiación no legítima en el Derecho histórico español, Sevilla, 1969.

${ }^{78}$ Respecto a estos últimos las Leyes de Toro habían fijado un nuevo concepto más amplio, más extenso, que el establecido por el derecho anterior, especialmente en relación a las Partidas. Aquí, siguiendo el derecho romano, se consideraban naturales a los nacidos de la propia barragana o concubina entendida como mujer libre, no impedida de contraer matrimonio, que está unida a un hombre de iguales condiciones conviviendo ambos exclusiva y maritalmente. La ley 11 de Toro, en un intento de ampliar al máximo el concepto de hijo natural, da cabida dentro del mismo a aquellos cuyos padres no hubieran podido contraer matrimonio en el momento de la concepción y sí en el del nacimiento. Según esta ley, es hijo natural aquel cuyos padres podían casar justamente y sin dispensación al tiempo que nacieron o fueron concebidos; el reconocimiento del padre era siempre preciso a menos que la madre fuera concubina única y retenida en la misma casa por el padre.

El concepto de naturalidad consagrado en 1505 se mantiene hasta el siglo XIX. La comisión especial de las Cortes encargadas del proyecto del Código civil en 1820 excluyó el tiempo del nacimiento para la calificación de los hijos, y propuso que sólo se tuvieran por naturales los ilegítimos habidos entre personas no impedidas de contraer matrimonio entre sí por razón de su estado ni por parentesco al tiempo de la concepción, lo que significa la aceptación plena de la solución adoptada por el Derecho canónico (E. Gacto Fernández, La filiación no legítima ..., p. 61 y ss.).

${ }^{79}$ Ibidem, p. 131.
} 
revelándole su secreto en caso de que pueda hacerlo sin peligro. No pudiendo obtener del hijo que acceda á su consejo, debe entonces restituir de sus propios bienes á los herederos del marido lo que se lleva el adulterino. Pero si no se atreviere ó no pudiere revelar el sigilo sin grave riesgo, y no tuviere bienes con que hacer dicha indemnización, bástale el arrepentimiento para estar segura en el fuero interno: Antonio Gomez, gl. Á las leyes 80,81 y 82 de Toro, número $75^{\prime \prime 80}$.

Pero $\mathrm{D}^{\mathrm{a}}$ Bernardina ha optado por la solución más comprensible, la que elegiría cualquier mujer en sus mismas circunstancias: dar por cierto que el niño es hijo legítimo del matrimonio, fuera así realmente, o no.

${ }^{80}$ J. Escriche, Diccionario razonado..., tomo primero, "adulterio", p. 322. 